\title{
Understanding the secondary system of therapeutic alliance in autism interventions from the perspectives of parents and caregivers
}

\author{
John Robert C. Rilveria ${ }^{1,2^{*}}$ (])
}

\author{
${ }^{*}$ Correspondence: \\ jcrilveria@up.edu.ph \\ ${ }^{1}$ Department of Psychology, \\ University of the Philippines \\ Diliman, National Capital \\ Region, Philippines \\ Full list of author information \\ is available at the end of the \\ article
}

\begin{abstract}
This study utilized a sequential explanatory mixed-methods design in understanding the secondary system of therapeutic alliance from the perspectives of parents and caregivers of children with autism. In the quantitative phase, data from the accomplished questionnaires of 124 parent-caregiver dyads were collected and analyzed. Four factors extracted from the literature: treatment attitude, treatment compliance, level of stress, and perceived autism severity were examined as possible predictors of parent-therapist alliance, caregiver-therapist alliance, and parent-caregiver alliance. In the qualitative phase, eight parent-caregiver dyads (who both scored high in their alliance with therapist, alliance with each other, treatment attitude, treatment compliance, and level of stress) were interviewed to probe on their experiences of alliance-building, parenting, and caregiving. The integration of both quantitative and qualitative data led to the formulation of a conceptual framework that explains how the factors influence the secondary system of therapeutic alliance. These findings emphasize that tapping into the personal experiences of parents and caregivers can help in identifying what they value in a working, therapeutic relationship. Moreover, communication, skills training, and feedback among therapists, parents, and caregivers are essential to enhance positive attitude toward treatment, promote compliance to treatment recommendations, and address sources of personal stress. Nevertheless, this study calls for future studies to build into the factors associated with the systemic therapeutic alliance and to implement intervention programs that may target issues relating to attitude toward treatment, compliance to treatment, and experience of parental and caregiver stress.
\end{abstract}

Keywords: Autism, Stress, Therapeutic alliance, Treatment attitude, Treatment compliance

\section{Background}

Autism spectrum disorder (ASD) is a complex neurodevelopmental disorder that develops during early childhood and dramatically impacts the person's quality of life (5th ed.; DSM-5; American Psychiatric Association, 2013). The growing prevalence and inherent complexity of ASD propel research endeavors in the biomedical and allied health fields that focus on its treatment and management (Raffin, 2001). As a result, evidencebased therapeutic interventions such as occupational therapy (for motor and sensory 
difficulties), speech-language therapy (for communicative rehabilitation), physical therapy (for musculoskeletal and mobility concerns), behavior therapy (for behavioral problems), and special education services (for educational or academic needs) are being utilized to manage ASD cases (DeFilippis \& Wagner, 2016).

Regardless of the type of intervention, a significant factor that influences the progress of treatment is therapeutic alliance (Lambert \& Ogles, 2004; Luborsky, 1994; Wampold, 2001). Therapeutic alliance has been traditionally defined as the functional, collaborative relationship between a service provider (e.g., therapist) and a client. From a structural perspective, Edward Bordin (1979) identified the triadic components of therapeutic alliance: agreement on goals, engagement on tasks, and formation of bond. However, this conceptualization of the therapeutic alliance is exclusive only to the relationship between the therapist and the client, also known as the traditional view of therapeutic alliance. Other relationships existing beyond the usual client-therapist relationship were neglected. In order to capture a more holistic view of therapeutic alliance, William Pinsof (1994) developed the Systemic Model of Therapeutic Alliance which enumerated four interpersonal alliance subsystems occurring in psychotherapy: alliance between the client and the therapist, alliance between the client and his/her significant others, alliance between the client's significant others and the therapist, and the group alliance.

\section{Systemic therapeutic alliance}

In the context of interventions for children with ASD, the concept of therapeutic alliance is multi-faceted and more complex as compared with the traditional view. The therapeutic alliance does not only exist within the therapist-child relationship, but also with the child's family (e.g., parents). Just as there is a demand in the work of the therapist to deal with the child, much of the therapy process also deals with the child's parents (Rodriguez, 2011). Children with autism are brought to therapy mostly based on the decision of the parents. Because of this, parents then become important allies in therapy (Weersing \& Weisz, 2002). This relationship between parents and therapists is described as a "facilitative condition that bolsters application of interventions and is therapeutic in its own right” (Alexander \& Dore, 1999).

Moreover, the presence of a hired caregiver or yaya broadens the network of the therapeutic alliance. In the Philippines, the caregivers or yaya are the unsung heroes as they are essential in assisting the unique needs of children with ASD. The caregiver or yaya may be an immediate or extended family member, a non-relative or romantic partner, or a family friend (Loper et al., 2014). Usually, for cases of children with autism, parents hire a caregiver or set of caregivers who can take care of their child full-time. An efficient yaya plays a huge role in implementing effective therapy for children with ASD. With a healthy relationship with the parents, the yaya is considered not only part of the child's team of therapists and teachers, but also an integral part of the child's family. During therapy sessions, the yaya is encouraged to attend and observe most of the center-based sessions and be immersed in the therapy program. In this way, the yaya can take over for the parent when the parent needs a break from the rigors of the child's program or when at work (Bermudo, 2010).

Applying Pinsof's framework in the context of autism interventions, the systemic alliance can be divided into two: primary and secondary systems of therapeutic alliance 
(Feinstein et al., 2009). The primary system of therapeutic alliance refers to a set of collaborative relationships that involves direct contact with the child-relationship between therapist and child and relationship between parent/caregiver and child. On the other hand, the secondary therapeutic alliance, also called the supporting alliance, refers to another set of collaborative relationship that does not involve a direct contact with the child but has an indirect influence on the child's progress-relationship between therapist and parent, relationship between therapist and caregiver, or relationship between parent and another caregiver (Karam et al., 2015). When taken together, these systems of therapeutic alliance form the systemic therapeutic alliance and the agents involved in each system form the child's system of care as shown in Fig. 1.

\section{Secondary system of therapeutic alliance}

For this study, the focus is on the secondary system of therapeutic alliance. The rationale behind giving importance to the secondary system of alliance revolved around the fact that children with ASD are surrounded by multiple therapeutic agents (parents, caregivers, and therapists) that do not only interact with the children, but also interact with one another (Pinsof, 1994). Furthermore, research studies revealed that positive therapeutic outcomes are not just influenced by the quality of relationship between the child and the therapist, but also by the quality of relationship among the care providers (Kazdin et al., 2006). Through regular therapy sessions with the child, consistent meetings with therapists, and coordination with the child's parents and caregivers, a healthy alliance among the members of treatment team is fostered (Alderson, 2009). When a healthy alliance is established, it is easier to implement a treatment plan and guarantee the treatment progress (Diguiseppe et al., 1996).

Therefore, it was essential to gather the perspectives of care providers in this study. In particular, parents and caregivers of children with autism were chosen as the target participants of this study because they are the care providers who spend more time with the

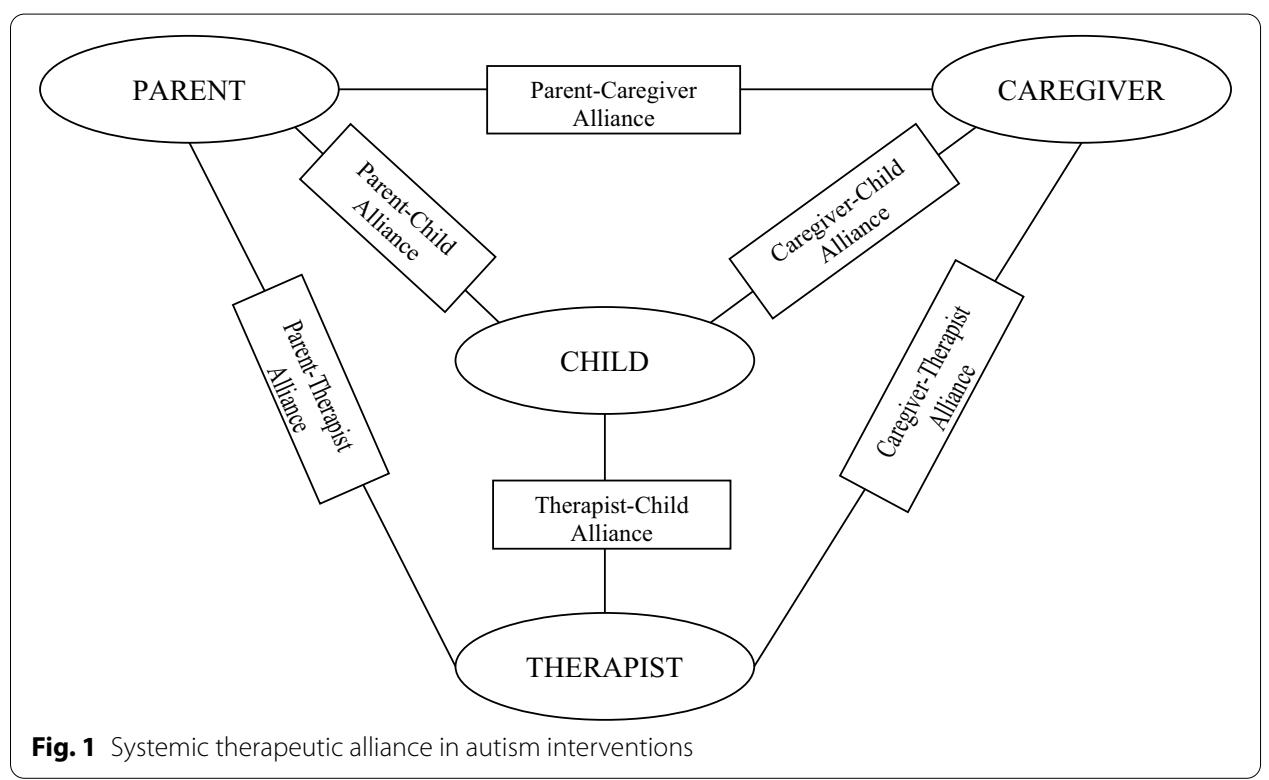


children outside the therapy setting as compared to therapists. Exploration of the views of these care providers regarding the development of relationships among one another is essential as they are given an active role in the initiation, agreement, and maintenance of therapy (Hawks, 2015).

\section{Factors associated with the secondary system of therapeutic alliance}

Reviewing the literature revealed that the major factors that influence the development and maintenance of the secondary system of therapeutic alliance are: parent's (DeVet et al., 2003; Kalyva, 2013) and caregiver's (Accurso, 2012) attitude toward child's treatment, parent (Hoagwood, 2005; Myers, 2008; Thompson et al., 2007) and caregiver (Shirk \& Karver, 2003) compliance, parental (Broggi \& Sabatelli, 2010) and caregiver (Rabideau, 2017; Rone-Adams et al., 2004) stress, and severity of the child's condition (Al-Dujaili \& Al-Mossawy, 2017).

Factors that are positively associated with therapeutic alliance are treatment attitude and treatment compliance. Treatment attitude of parents and caregivers refer to their acquired knowledge about treatment, recognition of the need for treatment, and interpersonal openness. These factors contribute to positive attitude toward treatment (Smithson, 2009). When parents and caregivers see the treatment as too irrelevant or demanding, they may form negative attitude toward treatment and may eventually terminate the treatment program (Kazdin et al., 1997). Nonetheless, when they see the therapist as a capable service provider and are satisfied with both the process and outcome of treatment, then a positive attitude toward the child's treatment is formed (Eyberg, 1993). Furthermore, due to perceived effectiveness and satisfaction on treatment, parents and caregivers who have formed a favorable attitude toward treatment are more likely to continue the implementation of such treatment than those who do not have positive attitude toward treatment (Taylor \& Antshel, 2019). Continuation of treatment characterized by agreement and compliance of parents leads to stronger relationships with the child's therapists (Myers, 2008). The concept of parent and caregiver treatment compliance refers to the degree by which parents and caregivers agree and follow the treatment recommendations by a professional and the extent to which these are practiced at home (Hock et al., 2015). The spectrum of compliance ranges from grateful acceptance of the professional advice on one end to total rejection of the recommendations on the other. Strong compliance can lead to better relationships with the professional and better outcomes for the child. Weak or total noncompliance, on the other hand, can lead to eventual termination of the professional relationship and removal of the child from the system of care (Davis, 2014; Dreyer et al., 2010).

In addition to the factors that facilitate therapeutic alliance, there are also factors that may hinder the quality of therapeutic alliance. Families of children diagnosed with a disability experience more instability, uncertainty, and dysfunction than typical families do (Watson et al., 2011). These experiences lead to increased levels of stress of parents and caregivers. Parental stress is defined as the parents' perception or feeling that the changes and demands associated with parenting exceed the available resources (health, financial, familial, etc.), and is considered a vital factor influencing child well-being (Mulsow et al., 2002). On the other hand, caregiver stress is defined as the caregiver's perception of the challenging physical, social, and emotional impact of caregiving on the 
caregiver's life (Amtmann et al., 2017). Research studies have consistently shown that the primary factor explaining the most variance of stress experienced by families of children with ASD is the severity of ASD symptoms due to associated behavior problems (Davis \& Carter, 2008). Severity of ASD refers to the degree or intensity of autism spectrum disorder as manifested by its core symptoms: impairment in social communication and interaction and repetitive behaviors and restricted interests and its associated problem behaviors: comorbidities, aggression, self-injury, and so forth (Hock et al., 2015).

\section{Research objectives}

The main objective for this study was to formulate a conceptual framework of the secondary system of therapeutic alliance. Specifically, experiences of parents and caregivers were assessed and probed to (1) identify the significant factors associated with the components of the secondary system of therapeutic alliance (parent-rated alliance with therapist, caregiver-rated alliance with therapist, parent-rated alliance with caregiver, and caregiver-rated alliance with parent); (2) gain information about how they form alliance with the therapist and with each other, and (3) gain an understanding on how the factors associated with the alliances can be utilized to improve the working relationship.

It is important to note that the therapists' perspectives were not included in this study. The alliances between parent/caregiver and therapist were only rated by the parent and caregiver respondents. No therapist-rated alliance data or narratives were collected. From a therapist's perspective, the therapeutic alliance is naturally a part and a necessary ingredient of the entire therapeutic process (Hawks, 2015). It is the professional obligation of the therapist to establish alliance, strengthen that alliance, and maintain the strength of that alliance up until the termination of the relationship (Ackerman \& Hilsenroth, 2003; Ardito \& Rabellino, 2011). The question now remains: how do therapists establish alliance with clients and from a systemic perspective, with other care providers surrounding their clients? Answers to this question may come from the people whom they form alliances with. Such perspectives are essential because they provide insight on how they perceive the alliance and what factors facilitate or interfere in building relationships with them. These data could provide multiple points of entry in establishing a good quality of relationship with them.

\section{Significance of the study}

Most studies on therapeutic alliance involving the child were focused on the primary system of therapeutic alliance (alliances with the child). Although these alliances are at the core of effective therapeutic interventions, research studies were conducted suggesting that child psychotherapy is most productive when the secondary system of therapeutic alliance (alliances that involve network of relationships not only with the child, but also among care providers) is also valued in the therapy process (Helps, 2016). However, research studies on the secondary system of therapeutic alliance have only received limited empirical or even theoretical attention (Feinstein et al., 2009). Hence, a significant contribution of this research would be to add to the existing pool of knowledge regarding secondary system of therapeutic alliance and place emphasis on its value to contribute to an effective system of care for the child. 
Moreover, there were relatively few research studies about child alliance as compared to adult alliance (Accurso \& Garland, 2015; Arnd-Caddigan, 2012; Shirk \& Karver, 2003; Walter \& Petr, 2006); moreso that there is not much local literature examining the concept of therapeutic alliance in the population of children with special health care needs. Exploring the secondary system of therapeutic alliance allows for the formulation of an integrated system of care (characterized by healthy alliances among parents, caregivers, and professionals) for children with ASD.

Furthermore, studies about therapeutic alliance dealt with mere description of the relationship and how it is related with treatment outcomes (Ardito \& Rabellino, 2011; Thompson et al., 2007). In this research, however, the focus was not on alliance-outcome relationship but on factors associated with establishing therapeutic alliance. Being able to identify such factors can provide a thorough understanding of the concept of therapeutic alliance and can serve as a guide for parents, caregivers, and professionals on how to utilize these factors to establish stronger alliances among one another and facilitate higher success of treatment.

This research study advocates for the inclusion of alliance-building among care providers in the entire treatment program (e.g., therapeutic alliance as a treatment goal). Most if not all autism treatment programs focus on decreasing challenging behaviors and increasing adaptive behaviors. However, the effectiveness of treatment is hugely attributable to the consistency of implementation of the treatment program, which necessitates collaboration and alliance among care providers (Baillargeon et al., 2005).

\section{Methodology}

\section{Study design}

A sequential explanatory mixed-methods design was used for this study. A mixedmethods design is appropriate given the objectives of the study. Although there are already factors influencing therapeutic alliance as mentioned in the literature, a deeper understanding on how these factors contribute to each component of the systemic therapeutic alliance is essential. The quantitative method aimed to test the hypotheses while the qualitative method aimed to explain and contextualize the quantitative results. Integrating the results can provide an organized, coherent framework of therapeutic alliance that can be utilized as a guiding framework for building alliances among providers of care.

Specifically, in the quantitative phase, four factors extracted from the literature: treatment attitude, treatment compliance, level of stress, and perceived ASD severity were assessed via hierarchical multiple regression on how well they can predict parent-therapist, caregiver-therapist, and parent-caregiver alliances. In the qualitative phase, parent-caregiver dyads were interviewed about their experiences of establishing a working relationship with the child's therapist and with each other. They were also asked about underlying bases for their treatment attitude and treatment compliance as well as underlying sources of their level of stress. Data from both quantitative and qualitative methods were integrated to formulate a conceptual framework of the secondary system of therapeutic alliance in the context of autism management. 
Table 1 Frequencies and percentages for categorical demographic variables $(n=124)$

\begin{tabular}{lll}
\hline Demographic & $f$ & $\%$ \\
\hline $\begin{array}{l}\text { Gender of parent } \\
\text { Female }\end{array}$ & 106 & 85.5 \\
$\quad$ Male & 18 & 14.5 \\
Gender of child & & \\
Female & 20 & 16.1 \\
Male & 104 & 83.9 \\
Socioeconomic status & & \\
High & 53 & 44 \\
Middle & 67 & 56 \\
Low & 0 & 0 \\
\hline
\end{tabular}

Table 2 Range, mean, and standard deviation for continuous demographic variables $(n=124)$

\begin{tabular}{lllll}
\hline Demographic & Minimum & Maximum & Mean & SD \\
\hline Age of parent & 28 & 64 & 44.92 & 9.197 \\
Age of caregiver & 22 & 57 & 34.34 & 8.440 \\
Years of service (caregiver) & 5 & 17 & 9.85 & 2.840 \\
Age of child & 4 & 12 & 8.70 & 1.887 \\
Years in therapy (child) & 2 & 10 & 7.30 & 2.028 \\
\hline
\end{tabular}

\section{Research participants}

In the quantitative phase, 124 parent-caregiver dyads were recruited via purposive and snowballing sampling. Participants met the following criteria:

1. Parents and caregivers (yaya) of children with ASD were recruited.

2. Parents and caregivers (yaya) must be living with the child under one roof.

3. Caregivers (yaya) must have been rendering paid caregiving services with the child for at least one year.

4. Parents and caregivers are affiliated with therapy centers in Metro Manila and children with ASD must be currently undergoing interventions (speech therapy, behavior therapy, occupational therapy, or child psychotherapy). Interventions must have been ongoing for at least 1 year.

Tables 1 and 2 provide the descriptive characteristics. Majority (85.5\%) of the parent respondents are mothers while $14.5 \%$ are fathers. The ages of parents range from 28 years to 64 years with a mean age of 44.92 years. In terms of the caregiver respondents, they are all females and their ages range from 22 years to 57 years with a mean age of 34.34 years. Overall, they have been rendering services for the corresponding family from 5 to 17 years with an average duration of 9.85 years. It is important to note that some caregivers have already been working for the family even before the child was born while there are others who just started working for the family years after the child was born. Moreover, the parent respondents were asked about demographic information regarding their child. Majority (83.9\%) of the children are males, whereas the remaining 
$16.2 \%$ are females. Their reported ages range from 4 years to 12 years with a mean age of 8.70 years. They have been undergoing therapy from 2 to 10 years with an average duration of 7.30 years. Lastly, $56 \%$ of the parent respondents reported that they belong to the middle-income bracket (monthly family income of more than or equal to P50,000 but less than or equal to P150,000) while $44 \%$ of them reported that they belong to the high-income group (monthly family income of more than or equal to P150,000). None of the parent respondents considered themselves to be in the low-income group (monthly family income of less than or equal to P20,000).

In the qualitative phase, eight parent-caregiver dyads who gained the top eight highest scores in the alliance measures (strong alliance) and factor measures (positive treatment attitude, positive treatment compliance, and high level of stress) were asked to participate in a short interview to probe on their experiences of alliance-building, parenting, and caregiving.

\section{Procedure}

Participants were recruited either immediately or at scheduled appointments. The participants (parents and caregivers of children with ASD) came from 30 therapy centers within Metro Manila (particularly, in areas of Caloocan City, Quezon City, Valenzuela City, and Makati City) all of which are private clinics. Sixteen of these therapy centers currently offer occupational therapy and speech-language therapy services while 14 therapy centers offer an occupational therapy, speech-language therapy, behavior therapy and special education tutorial services. Permission from these therapy centers were sought to provide referrals of potential participants for my study. Via purposive sampling (purposively selecting participants that meet the inclusion criteria), 87 parent-caregiver dyads were recruited. From these participants, they were also able to help find other people they personally know who can participate in the research. Through this snowballing approach, 44 more parent-caregiver dyads were included in the study. A total of 131 parent-caregiver dyads participated in this study.

Informed consent forms explaining the objectives and process of research, risks and benefits of participating in research, rights as a research participant, and privacy and confidentiality of data were provided to the participants.

After signing the consent form, a demographic questionnaire and the corresponding measurement scales to the parents and caregivers were administered in a face-to-face, pen and paper format. Answering the tests took about fifteen to twenty minutes. Among the 131 dyads of parent and caregiver respondents, 124 parent-caregiver dyads were able to accomplish the tests. Only the completed tests were used for data analysis. Therefore, a total of 124 parent-caregiver dyads became part of the research output. From the 124 parent-caregiver dyads, 8 parent-caregiver dyads were invited for an interview. These are the respondents who scored very high on the alliance and factor measures. The interviews were recorded and transcribed. The parents and caregivers in each dyad were interviewed separately in order to facilitate a more open response especially when talking about their experiences of establishing and maintaining a working relationship not only with the child's therapist, but also with each other. Each interview session lasted for $1 \mathrm{~h}$ to $1.5 \mathrm{~h}$. 


\section{Research instruments}

A demographic questionnaire and a set of measurement scales were administered as tools for gathering data. The demographic questionnaire contained information about age and sex of respondents, age and sex of child involved, number of years in service (for caregivers), number of years receiving services (for parents), and socioeconomic status of the family. On the other hand, the measurement scales administered to both parents and caregivers were as follows: (1) Therapeutic Alliance Scale for Caregivers and Parents; (2) Parent-Caregiver Relationship Scale; (3) Therapy Attitude Inventory; (4) General Adherence Scale; (5) Caregiver Stress Scale, and (6) Impact of ASD symptoms Scale.

\section{Parent-therapist and caregiver-therapist alliances}

The parent-therapist and caregiver-therapist alliances were measured using the Therapeutic Alliance Scale for Caregivers and Parents developed by Accurso et al. (2013). It is a 12-item scale rated on a 4-point scale. Total scores range from 12 to 48. The total score can be computed as the sum of all items, with items 2, 5, 7, 8 and 11 items being reversed-scored.

There is good internal consistency of the scale (ranging from 0.80-0.90). Moreover, predictive validity was established through regressions with related factors. High parent/caregiver-therapist alliance is a significant predictor of attended sessions $(B=0.62$, $\mathrm{SE}=0.18, p<0.001)$ and perceived improvement $(B=0.03, \mathrm{SE}=0.01, p<0.005)$. In addition, poor alliance is a significant predictor $(B=0.07, \mathrm{SE}=0.03, p<0.01)$ of drop-out from therapy (Accurso et al., 2013).

\section{Parent-caregiver alliance}

The parent-caregiver alliance was measured using the Parent-Caregiver Relationship Scale by Elicker et al. (1997) for both parents and caregivers. It is a 35-item scale measured on a 5-point Likert scale (from 1-strongly disagree to 5-strongly disagree). Total scores are computed by adding up the ratings across the items, with high scores indicating good relationship quality and low scores indicating poor relationship quality. Two equivalent forms are created for both parent and caregiver respondents.

In terms of its psychometric properties, factorial validity was established through principal components analysis and yielded three significant factors for the parent scale: Confidence, Collaboration, and Affiliation and three factors for the caregiver scale: Confidence, Collaboration, and Caring. The three-factor solutions accounted for $45 \%$ of the variance in the parent scale and $48 \%$ of the variance in the caregiver scale. Reliability was established through inter-item consistency yielding an overall Cronbach's alpha of 0.93 for the parent scale and 0.94 for the caregiver scale. Alphas for the subscales were 0.91 for parent and 0.92 caregiver confidence, 0.90 for both parent and caregiver collaboration, and 0.75 for parent affiliation and 0.84 for caregiver affiliation (Elicker et al., 1997).

\section{Parent and caregiver treatment attitude}

The parents' and caregivers' attitude toward treatment were assessed using the Therapy Attitude Inventory developed by Eyberg and Johnson (1974). It is a 10-item measure scored on a five-point scale from 1 (dissatisfaction with treatment or worsening of problems) to 5 (satisfaction with treatment or improvement of problems). 
Reliability coefficient for the scale ranges from 0.88 to 0.91 which indicate very high internal consistency. Moreover, factor analysis yielded two factors: satisfaction with treatment outcomes (alpha 0.93) and satisfaction with treatment process (alpha 0.73). These two factors contribute to parents' and caregiver's attitude toward treatment (Brestan et al., 1999).

\section{Parent and caregiver treatment compliance}

To measure parent and caregiver compliance, the General Adherence Scale, a subscale from the Medical Outcomes Study was used. It is a 6-point Likert five-item scale that measures self-reported treatment compliance. The first and third items are reversescored because they are negative statements. The total score is calculated as the average of the five items (maximum of 6 and minimum of 1). High scores indicate high parent/ caregiver compliance while lower scores indicate low parent/caregiver compliance.

In the study done by Hock et al. (2015) with parental compliance to treatments of children with autism, the scale has very high internal consistency (Cronbach's alpha) ranging from 0.85 to 0.88 across four treatment types: medication treatments, behavioral treatments (e.g., Applied Behavior Analysis), developmental treatments (e.g., speech and occupational therapy), and alternative treatments (dietary or nutritional treatments).

\section{Parental and caregiver stress}

To measure the levels of stress for both parents and caregivers, the Caregiver Stress Scale developed by Amtmann et al. (2017) was used for both parents and caregivers. It is a 19-item scale rated on a 5-point Likert format which is intended to be used for caregivers (either a family member or guardian) of children with special health care needs and/ or behavioral problems. It has good construct validity as it significantly correlates with the Pediatric Caregiver Burden Scale $(r=0.7)$ and satisfactory discriminant validity due to significant differences between caregivers of children with special needs $(M=58.7$, $\mathrm{SD}=6.8$ ) reporting higher stress levels than caregivers of children with no special needs $(M=46.1, \mathrm{SD}=9.4)$. It has excellent test-retest reliability, with a coefficient of 0.97 (Amtmann et al., 2017). This scale was originally meant to be used for only caregivers rendering unpaid caregiving services, usually the parent or legal guardian. In this study, however, I decided to use this scale to also measure the level of stress of caregivers of children rendering paid caregiving services as the items of this scale are deemed applicable for hired family caregivers.

\section{Perceived autism severity}

Lastly, the perceived ASD severity was measured using the 20-item Impact of ASD symptoms scale. This is a subscale of the Quality of Life in Autism Questionnaire developed by Eapen et al. (2014). This was designed to assess parents' and caregivers' perception of how problematic or severe the child's autism-specific difficulties are for them.

Rated on a five-point Likert format (with 1-not much of a problem for me to 5-very much of a problem for me), scores can range from 20 to 100, with lower scores signifying fewer problems or less perceived severity regarding the child's ASD-related behaviors. The internal consistency coefficients for this subscale is 0.92 for the ASD group (children with ASD) and 0.86 for the control group (children without ASD or any developmental 
disability). In terms of its discriminant validity, this subscale was able to significantly differentiate ratings of parents in the ASD group (reporting higher ratings) and parents in the control group (reporting lower ratings) via independent samples t-test. Moreover, its convergent validity was established through the significant correlations found with the Social Communication Questionnaire $(r=-0.37)$ and the Vineland Adaptive Behavior Scale-Maladaptive behavior index $(\mathrm{r}=-0.37)$.

\section{Cross-cultural reliability of the scales}

Reliability analyses were performed to establish the cross-cultural reliability information of the Therapeutical Alliance Scale for Caregivers and Parents, Parent-Caregiver Relationship Scale, Therapy Attitude Inventory, General Adherence Scale, Caregiver Stress Scale, and Impact of ASD Symptoms scale on how well the items between scales are internally consistent when administered in the Filipino population. The results showed great internal consistencies of greater than 0.6 .

\section{Interview guide}

For the qualitative part of the study, an interview guide was used. It consists of five general questions with corresponding probing questions each. The first question was intended to gather information about parents' and caregivers' experiences of building and maintaining a good relationship with the child's therapist. The second question was about parents' and caregivers' experiences of building and maintaining a good working relationship with each other. The third question and fourth questions explored the bases for the parents' and caregivers' positive attitude toward the child's treatment and positive compliance to treatment, respectively. Finally, the fifth question focused on the sources of parental and caregiver stress in relation to parenting and caregiving.

\section{Data analysis}

\section{Quantitative phase}

Data from the demographic questionnaire and scores from the measurement scales were analyzed using a statistical tool (SPSS v. 22). Descriptive statistics in the demographic data were explored to provide a contextual description of the participants that were studied. Likewise, the scores from the measurement scales were examined via descriptive statistics to look at the variability and normality of score distributions. Then, a hierarchical multiple regression was performed to test the variables that can significantly predict each component of the secondary therapeutic alliance. The presence of outliers, homoscedasticity of residual variances, and non-multicollinearity of predictors were assessed to support the use of multiple regression as a method of analysis.

In the analysis, four regression models were obtained: two from the parents' perspective (explaining parent's alliance with therapist and caregiver) and the other two from the caregivers' perspective (explaining caregiver's alliance with therapist and parent). The dependent variables (outcomes) were the alliance measures (parent-rated alliance with therapist, parent-rated alliance with caregiver, caregiver-rated alliance with therapist and caregiver-rated alliance with parent) while the independent variables (predictors) were the: treatment attitude, treatment compliance, level of stress, and perceived ASD severity. 


\section{Qualitative phase}

Data from the interview were analyzed and themes were extracted via thematic analysis. Narratives of both parents and caregivers regarding their perception of the relationship with therapist and with each other, their bases for their attitude and compliance in treatment, and their experience of stress were compared. These were used as supporting information to gain a comprehensive understanding of the results of the quantitative analysis.

\section{Results and discussion}

\section{Descriptive information}

Mean scores of the respondents across the scale variables indicate good alliance with their therapist, good alliance with each other, positive attitude toward treatment, average treatment compliance, above average stress levels, and ASD severity perceived as problematic (see Table 3).

The good quality of alliance as perceived by parents and caregivers with the child's therapist may have been influenced by the duration of therapy services. There are studies looking at the significant relationship between treatment retention and therapeutic alliance particularly in the context of child psychotherapy. Parents and caregivers who perceive a good quality of alliance with the child's therapist are more likely to continue with the treatment intervention-thus, lengthening the duration of therapy (Kazdin, 2006; Thompson et al., 2007). Likewise, the good quality of alliance perceived by parents and caregivers for each other can also be related to the number of years the caregiver has spent for the family. In the study done by Elicker et al. (1997), the scores reported by both parents and caregivers using the Parent-Caregiver Rating Scale are significantly correlated with the number of months the caregiver has rendered services for the family. Therefore, the therapeutic alliance may be more likely to be perceived as generally positive the longer the working relationship lasts.

Furthermore, both parents and caregivers reported above average stress levels at the time of measurement. This makes sense because studies have shown that parents and caregivers of children with autism have significantly higher stress levels than parents and

Table 3 Mean scores, standard deviations, skewness, and kurtosis for scale variables $(n=124)$

\begin{tabular}{|c|c|c|c|c|}
\hline Scale variables & Mean & SD & Skewness & Kurtosis \\
\hline Parent-rated alliance with therapist & 34.15 & 11.503 & -0.304 & -0.805 \\
\hline Caregiver-rated alliance with therapist & 36.27 & 11.878 & -0.373 & -0.739 \\
\hline Parent-rated alliance with caregiver & 129.76 & 27.944 & -0.056 & -1.104 \\
\hline Caregiver-rated alliance with parent & 120.08 & 32.138 & 0.122 & -0.784 \\
\hline Treatment attitude (parent) & 31.55 & 11.385 & -0.009 & -1.3 \\
\hline Treatment attitude (caregiver) & 32.65 & 10.1 & -0.039 & -0.954 \\
\hline Treatment compliance (parent) & 3.49 & 1.423 & -0.302 & -0.93 \\
\hline Treatment compliance (caregiver) & 3.72 & 1.665 & -0.421 & -1.004 \\
\hline Parental stress & 54.74 & 17.553 & 0.158 & -0.538 \\
\hline Caregiver stress & 55.58 & 18.970 & 0.362 & -1.027 \\
\hline ASD severity (parent) & 66.95 & 13.123 & -0.087 & 0.067 \\
\hline ASD severity (caregiver) & 59.23 & 17.305 & -0.055 & -0.78 \\
\hline
\end{tabular}


Table 4 Final regression models predicting parent-rated alliance with therapist and parent-rated alliance with caregiver

\begin{tabular}{llllllllll}
\hline & \multicolumn{4}{l}{ Parent-rated alliance with therapist } & \multicolumn{5}{c}{ Parent-rated alliance with caregiver } \\
\hline Predictors & $\beta$ & SE & $R^{2}$ & $F(d f)$ & $\beta$ & SE & $R^{2}$ & $F(d f)$ \\
Treatment attitude & $0.306^{*}$ & 0.092 & 0.324 & $13.574(2121)^{*}$ & - & - & & \\
Treatment compliance & $0.336^{*}$ & 0.737 & & & - & - & & \\
Parental stress & - & - & & & $-0.552^{*}$ & 0.119 & 0.305 & $53.535(1122)^{*}$ \\
\hline$p<0.01$ & & & & & & & &
\end{tabular}

Table 5 Final regression models predicting caregiver-rated alliance with therapist and caregiverrated alliance with parent

\begin{tabular}{|c|c|c|c|c|c|c|c|c|}
\hline \multirow[b]{2}{*}{$\begin{array}{l}\text { Predic- } \\
\text { tors }\end{array}$} & \multicolumn{4}{|c|}{ Caregiver-rated alliance with therapist } & \multicolumn{3}{|c|}{ Caregiver-rated alliance with parent } & \multirow[b]{2}{*}{$F(d f)$} \\
\hline & $\beta$ & SE & $R^{2}$ & $F(d f)$ & $\beta$ & SE & $R^{2}$ & \\
\hline $\begin{array}{l}\text { Treat- } \\
\text { ment } \\
\text { attitude }\end{array}$ & $0.366^{*}$ & 0.089 & 0.456 & $25.805(2,121)^{* *}$ & - & - & & \\
\hline $\begin{array}{l}\text { Treat- } \\
\text { ment } \\
\text { compli- } \\
\text { ance }\end{array}$ & $0.404^{* *}$ & 0.541 & & & - & - & & \\
\hline $\begin{array}{l}\text { Parental } \\
\text { stress }\end{array}$ & - & - & & & $-0.565^{* *}$ & 0.127 & 0.319 & $\begin{array}{l}57.257 \\
(1,122)^{* *}\end{array}$ \\
\hline
\end{tabular}

caregivers of typically developing children (Brobst et al., 2009; Krakovich et al., 2016; Wolf et al., 1989). Likewise, similar significant findings about stress levels were observed when families of children with ASD are compared with families of children with other forms of disability such as intellectual disability, Down's Syndrome, cerebral palsy, and fragile X syndrome (Abbeduto et al., 2004; Blacher \& McIntyre, 2006; Bouma \& Schweitzer, 1990; Dabrowska \& Pisula, 2010).

\section{Quantitative results}

It is quite notable that the regression models for both parent (see Table 4) and caregiver (see Table 5) ratings resemble each other in terms of the significant predictors (treatment attitude, treatment compliance, and stress).

\section{Parent ratings}

Treatment attitude and treatment compliance are significant predictors of parent-rated alliance with therapist $\left[F(2,121)=29.008, p<0.01, R^{2}=0.324\right]$. This means that $32.4 \%$ of changes in parent-rated alliance with therapist is accounted for by changes in parent's treatment attitude $(\beta=0.306, p<0.01)$ and treatment compliance $(\beta=0.336, p<0.01)$. Furthermore, in terms of parent-rated alliance with caregiver, parental stress turned out to be a significant negative predictor $\left[F(1,122)=53.535, p<0.01, R^{2}=0.305\right]$. This shows that changes in the parent's stress levels $(\beta=-0.552, p<0.01)$ can explain $30.5 \%$ of changes in parent-rated alliance with caregiver. 


\section{Caregiver ratings}

Likewise from the perspective of the caregivers, their treatment attitude and treatment compliance are significant predictors of caregiver-rated alliance with therapist $[F(2,121)=50.732$, $\left.p<0.01, R^{2}=0.456\right]$. This indicates that $45.6 \%$ of changes in caregiver-rated alliance with therapist is explained by changes in caregiver's treatment attitude $(\beta=0.366, p<0.01)$ and treatment compliance $(\beta=0.404, p<0.01)$. Then with regard to caregiver-rated alliance with parent, caregiver stress is also a significant negative predictor $\left[F(1,122)=57.257, p<0.01, R^{2}\right.$ $=0.319]$. This shows that $31.9 \%$ of changes in caregiver-rated alliance with parent can be attributed to changes in the caregiver's stress levels $(\beta=-0.565, p<0.01)$.

\section{Qualitative results}

While there is a similarity in the regression models for both parent and caregiver ratings of alliances, the subsequent qualitative analyses revealed striking differences with regard to (a) how parents and caregivers perceive the therapeutic relationship; (b) bases of their attitude and compliance to treatment, and (c) sources of stress.

\section{Comparing parents' and caregivers' perception of alliance toward the therapist}

The parent-rated alliance with therapist is highly attributed to an aspect of relationship that involve "working together" and "problem-solving". On the other hand, the caregiver-rated alliance with therapist is highly accounted by the caregivers' positive feelings toward the therapist. The following are some of the responses (translated in English) from the interview:

Parent responses:

We always have time to discuss things and arrive at plans especially on addressing behavioral problems of my kid.

There has been no difficulty in working with my child's therapist. Both of us are very open to options concerning my child.

I can see the effort of Teacher (name of therapist) in really creating a good treatment plan for my kid. It's really motivating for me to work with him.

Teacher (name of therapist) always brings up the idea of collaboration and solving problems together. Being involved with my child's therapy program makes me feel confident about my child's progress.

Caregiver responses:

I like spending time with Teacher (name of the child's therapist). She is very approachable and has sense of humor.

It makes me feel good that he recognizes and praises my efforts in taking care of (name of child).

I am happy that he is the therapist of (name of child). He is very supportive and always checks up on me.

I always look forward to therapy sessions because not only that (name of child) is learning but he cares for me as well. I can open up to him about my difficulties in taking care of (name of child). 


\section{Comparing parents' and caregivers' perception of relationship with each other}

The prevalent theme in the parents' narratives about their relationship with the caregivers revolves around their confidence in the knowledge and skills of the caregiver in taking care of the child. For caregivers, they perceive a good relationship when the parents are seen as helpful and reliable. These themes were extracted from the following responses (translated in English):

Parent responses:

I can see that my child's caregiver has the adequate knowledge and skills in taking care of and teaching my child.

I am confident in the way my child's caregiver is taking care of my child.

It was very easy for me to build a good relationship with my child's caregiver because she knows how to take care of my children.

Caregiver responses:

I don't have problems with Mrs. (child's mother) because I know I can count on her whenever I need help.

I know that I'm not alone in this... Mr. and Mrs. (child's parents) are always there to help me and teach me.

I even consider myself lucky that I am working with a family who guides and helps me with my tasks.

\section{Comparing parents' and caregivers' attitude toward treatment}

For parents, their positive attitude toward treatment is based on two factors: perceived competencies of the therapist and perceived improvement of the child. On the other hand, a factor that greatly contributes to the positive attitudes of caregivers toward treatment is their acquisition of skills and knowledge relevant to autism management. The following are their responses (translated in English) from the interview:

Parent responses:

After reviewing the qualifications and credentials of my child's therapist, if I know that the therapist is qualified, then I can trust the treatment program.

The educational background and training of the therapist matter to me. In that way, I can be confident about the kind of treatment we are working on.

If I see progress on my child's behavior, I know that the treatment is working and I can depend on it.

I have positive attitude regarding the treatment because I can see to it that our treatment goals are being checked.

Caregiver responses:

I feel positive about the treatment because I learned a lot of things-I learned how to properly address (name of child)'s tantrums and violent behaviors.

I am now able to teach (name of child) simple skills like sitting longer while eating, taking turns while playing, and using words when requesting.

I feel more confident in my ability to handle the child better than before. 


\section{Comparing parents' and caregivers' compliance to treatment}

In terms of treatment compliance, both parents and caregivers reported that their compliance to the treatment plan is influenced by two factors: environmental contingencies (schedule of skill practice and opportunities for practice) and perceived improvement of the child. Below are their responses (translated in English):

Parent responses:

I have to make sure I spend time with my kid to practice the skills taught in therapy. Even if I don't get to set a specific time and place for practicing the skills, I take advantage of opportunities where I can teach my child. When (name of child) is pointing at something, even if I know what he meant, I prompt him to use his words. If I observe my child being responsive to therapy, then it makes me more interested in trying the same approach outside therapy.

Caregiver responses:

I follow what Teacher (name of therapist) told me. We set the time for play and learning.

Even in playtime and eating time, I apply the skills they are practicing in therapy.

I can see improvements with (name of child) in therapy. So it only makes sense for me to learn how it is being done so I can practice it when I interact with (name of child).

\section{Comparing parents' and caregivers' sources of stress}

The sources of parental and caregiver stress were also identified. For parents, they specified the stress related to parenting as a "limiting or restricting responsibility". While for caregivers, their stress is related to physical exhaustion as a consequence of taking care of the child. Below are their responses (translated in English):

Parent responses:

I can say that having (name of child), it limits my career opportunities. I have more responsibility in making sure that my son is able to live a good life.

Raising a child with autism is very stressful because I don't get to take care of myself fully. I have to sacrifice my own leisure and enjoyment because I have a responsibility to take. My attention and goals are now devoted to my son.

Mostly, it becomes difficult for me to enjoy things I used to enjoy like time for my husband, for my friends...I always have my daughter in mind wherever I go.

Caregiver responses:

It's very tiring to take care of a child with autism while being expected to do household chores as well.

There are times that I don't get enough sleep because I have to spend a lot of time taking care of the child.

It's very hard to balance between doing my job and being burned-out. 


\section{Integration}

Integrating the results of quantitative and qualitative analyses led to the formulation of a conceptual framework as illustrated in Fig. 2.

The parent-therapist alliance is heavily influenced by how well they work together and collaborate with regard to the child's care and treatment. On the other hand, the caregiver-therapist alliance is mostly pronounced by how well the caregiver likes the therapist in terms of preference and emotional investment. Interestingly, these themes that emerged from the narratives of parents and caregivers are analogous to Bordin's (1979) triadic components of therapeutic alliance-agreement on goals and engagement on tasks for parenttherapist alliance and formation of emotional bond for caregiver-therapist alliance.

Dwelling on the factors influencing alliances with therapist, when parents and caregivers have favorable attitude toward treatment, they are more likely to develop stronger alliance with the child's therapist than those with negative attitude toward treatment. This corroborated the research study of Accurso (2012), stating that positive treatment attitude of parents and caregivers facilitate the formation of alliance with therapist.

Since treatment attitude is a predictor of changes in alliance between parents/caregivers and therapist, this can serve as a point of entry in building such alliances. Based on the qualitative data, positive treatment attitude of parents is coming from perceived competencies of the therapist as well as perceived improvement of the

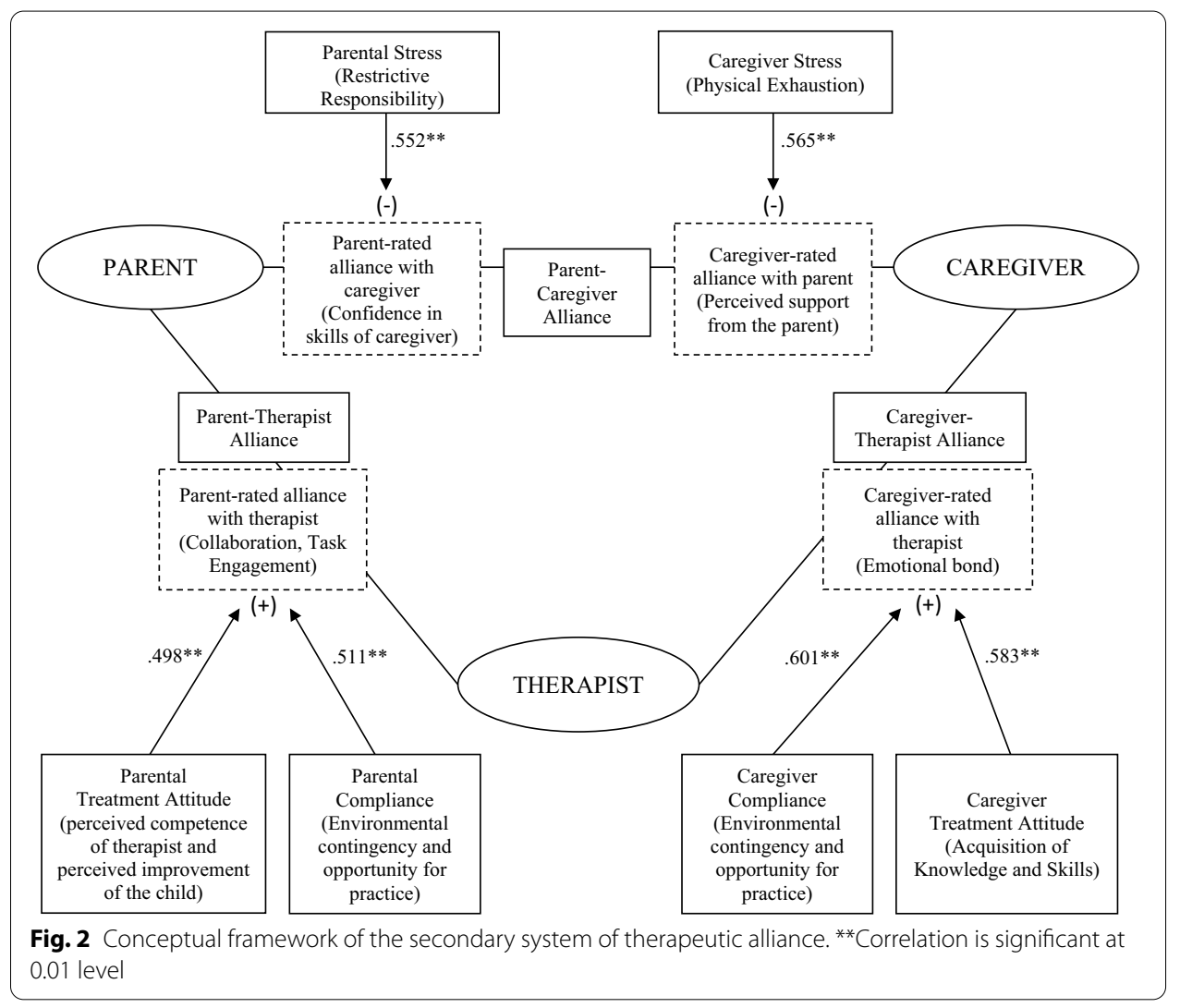


child. This is also similar to the previous studies done by Eyberg (1993), DeVet et al. (2003), and Kalyva (2013) stating that when parents witness improvements on the child since the therapy started, then they would favor the continuation of therapy. On the other hand, the positive attitude of caregivers is based on acquisition of skills and knowledge. This result is similar to the findings of Smithson (2009), stating that treatment attitude has three components: expectation and recognition of the need for treatment, acquisition of knowledge about treatment, and openness about treatment. Therefore, professionals working with parents and caregivers can tap into these information to facilitate positive attitude toward treatment and eventually build alliance with them. Programs that raise awareness regarding child mental health care particularly autism management and interventions can be implemented as these can promote positive attitude toward treatment-making parents and caregivers perceive the need for treatment, allowing them to be mindful that there are effective treatment approaches to autism, and equipping them with the necessary knowledge and skills that can be applied in child care. Integrating the quantitative findings with the qualitative data on the perception of alliances, therapists can a) focus on tasks and goals for parents by treating them as working partners (e.g., regularly updating them with progress reports and upgrade or modification of treatment plan) and b) focus on formation of bond for caregivers by being supportive allies in therapy (e.g., providing constant emotional support, appreciating their efforts while teaching).

Aside from treatment attitude, treatment compliance was revealed to be an additional significant predictor of both parent-rated and caregiver-rated alliance with therapist. The set of predictors involving both attitude and compliance makes a better model than either attitude alone or compliance alone. This makes sense because according to the literature, a positive attitude toward treatment makes parents and caregivers trust the therapist and become more likely to comply with treatment recommendations which then leads to stronger alliance (Accurso, 2012; Hoagwood, 2005; Myers, 2008).

Based on the qualitative data, parents and caregivers are more likely to comply if they have time and opportunities to practice the skills taught in therapy. Therefore, therapists are encouraged to create a simple yet effective home program from which parents and caregivers can easily follow and would not take too much time preparing or doing. As a result, parents and caregivers will not have difficulty complying and will be more likely to implement the program consistently. In case problems arise in terms of complying with the treatment recommendations (e.g., having difficulty implementing the program or lack of time in carrying out the assigned tasks), the parents and caregivers are encouraged to communicate with the therapists and vice versa in order to make the necessary adjustments to the program and formulate the best schedule or time allotment as to when and how they can implement the program at home (Menahem \& Halasz, 2000).

It is interesting to note that neither the level of parental and caregiver stress nor their perceived severity of the child's condition came out to be significant predictors of the alliance with therapist-contrary to the findings of Broggi and Sabatelli (2010) and Rone-Adams et al. (2004). This only means that regardless of the stress experienced by parents and caregivers and no matter how severe they perceive the child's condition to be, they are still capable of forming strong alliance with the child's 
therapist. This implies hope and optimism for therapists in their efforts to build healthy relationships with parents and caregivers of children with autism.

With respect to the parent-caregiver alliance, the qualitative data revealed that parents perceive the working relationship on the basis of how confident they are with the caregiver's skills. This information can be tied with what was revealed earlier about caregiver-therapist alliance and caregiver's attitude toward treatment. If caregivers are given the opportunity to be equipped with the necessary skills and knowledge in taking care of the child, thus enhancing positive attitude toward treatment, then it will not only facilitate the formation of caregiver-therapist alliance, but also the formation of the parent-caregiver alliance. On the other hand, for the caregivers, they perceive the working relationship with parents based on how supportive the parents are. This can be connected to the results of the regression models-with parental and caregiver stress as a negative predictor of their alliance. Experiencing a great deal of stress may compromise the quality of their relationship. Stress as an influential factor in the development of alliance between parents and caregivers was also confirmed in a previous study (Rabideau, 2017), stating that high levels of stress compromises the quality of working relationship between parents and caregivers of children with disabilities.

Based on the qualitative data, the parental stress is mainly about feelings of being limited or restricted as a consequence of parenting. This result is related to the study discovered by Sullivan (2011), stating that the main source of stress for parents of children with autism was the emotional strain experienced by the family. To overcome this problem, a family therapy may be advised to provide opportunity for parents to discuss their concerns and work on minimizing the burden of parenting.

For the caregivers, it is obvious that their occupation takes a toll on their health and well-being. The qualitative data revealed that the caregiver stress is about the physical exhaustion experienced by the caregivers. This supports the results of the study done by Kheir et al. (2012) stating that caregiver stress is mainly due to the psychosocial burden and lack of support associated with taking care of the child with autism. To address this, parents are encouraged to be aware and sensitive of the possible burn-out or strain experienced by caregivers and be able to provide the support that they need-e.g., allowing day-offs, delegating tasks, or reducing the workload.

It is very clear that there are multiple points of entry that care providers such as parents, caregivers, and therapists can utilize in order build and maintain healthy alliances. Furthermore, these findings support the idea that a systemic approach to therapeutic alliance involves a therapeutic benefit not only for the child, but for the care providers as well.

\section{Limitations}

There are several limitations to this study that warrant the need for further investigation and expansion of this topic. First, in terms of the sample demographic, most of the parent respondents are mothers. It would be interesting to include more fathers in the system. A lot of barriers exist in terms of engaging fathers in coparenting responsibility and parenting interventions (Panter-Brick et al., 2014). Thus, paternal perspectives in terms of building alliances with therapists and caregivers are as essential. Moreover, the parents that were recruited in this study belong to the middle to high socioeconomic group due to the financial demand of hiring a caregiver and investing in therapy. It would then 
be interesting to compare middle- to high-income families who can hire a caregiver and low-income families who can only afford to have a relative or kin as their caregiver. Finally, the parent-caregiver dyads who participated in this study reported certain number of years in therapy and caregiving $(M=7.30$ and $M=9.85$, respectively). This long duration in both therapy and caregiving may have contributed to the mostly reported positive alliance with therapists and positive alliance between parents and caregivers. This study is limited in establishing patterns of alliances that were already present (characterized by high ratings of alliances) in the first place. It would also be interesting to look at factors influencing early alliance (characterized by low ratings of alliances). It is also worth noting that some caregiver participants are already working for the family before the child (with ASD) was born while there are some who just started working for the family years after the child (with ASD) was born. The former implies an existing working relationship between parents and caregivers that may be distinct from the latter. This within-group variability was not addressed in the study.

Second, in terms of the study design, therapeutic alliance was measured in a crosssectional manner. The concept of therapeutic alliance is an evolving process that necessitates continuous measurement over time (Karam et al., 2015). Therefore, further studies are recommended to make use of longitudinal approaches in quantifying therapeutic alliance and see if the scores on therapeutic alliance and factors associated with it vary across time. The stages of change from the establishment, strengthening, to maintenance, rupture, and repair of alliance may be captured using this approach.

Third, there is a need for more culturally appropriate measures for caregivers, specifically for paid caregivers. For instance, the Parent-Caregiver Relationship Scale was developed to measure alliance between parents and caregivers. It was initially administered to parents and non-paid caregivers of children. Although it has already been used for professional caregivers (Elicker et al., 1997), there are items in the scale that may not be applicable in the context of paid caregivers in the Philippines.

Lastly, the regression models in the study still have a certain amount of variance unaccounted for. This only means that there are still other potential variables (mediating or predictors) not included in the study that may contribute to therapeutic alliance. Further expansion of the qualitative phase of the study may be able to capture other potential factors influencing the different forms of alliances.

\section{Directions for future research}

The study began investigating the components of the secondary system of therapeutic alliance from the perspective of parents and caregivers through understanding their treatment attitude, treatment compliance, and level of stress. Since three factors that are significantly associated with therapeutic alliance have been identified, future studies should include exploration of other variables related to these factors that can be added to the model. Furthermore, proposals for interventions with regard to increasing treatment attitude and compliance and reducing stress levels are interesting areas for future research because these may help in promoting alliances among parents, caregivers, and therapists. 
Future studies on including the perspectives of other agents involved in the child's system of care (other relatives, school teachers, physicians, etc.) are recommended as these people are also part of the secondary or probably higher-order system of therapeutic alliance. The expansion of the model can provide additional information and other points of entry for building alliances among care providers of children with autism.

\section{Conclusion}

A great deal of research studies would support that therapeutic outcome is a function of therapeutic alliance. Furthermore, a systemic approach in looking at therapeutic alliance is essential in capturing the therapeutic processes involved in child psychotherapy, particularly in interventions for children with autism.

Children with autism live in a multi-system environment, surrounded by multiple providers of care. In order to ensure the quality of childcare, strong alliances among these care providers must be established and maintained. In working with children with autism, there are three people mostly involved in the child's system of care: the child's parents, the caregivers, and the therapists. Among these three, the parents and caregivers spend most of the time taking care of the child. So, their perspectives with regard to how they perceive and establish therapeutic alliance can be utilized to encourage including alliance-building as part of the treatment program in the context of autism management.

Positive attitude toward treatment and positive compliance were identified as significant factors influencing the development of a healthy alliance of parents and caregivers with the child's therapist. Moreover, high levels of stress can interfere in the relationship between parents and caregivers.

This research study highlights the importance of the attitudes, behaviors, and experiences of parents and caregivers of children with autism. The conceptual framework based on the findings of this study can provide information for therapists, parents, and caregivers to utilize these factors and know where to invest efforts in building alliances with one another. This study advocates the concept of secondary therapeutic alliance that is not only therapeutic for the child (receiver of care) but also beneficial for the providers of care.

Nonetheless, this exploratory study calls for future studies that may continue to build into the factors influencing the systemic therapeutic alliance and implementation of intervention programs that may target issues relating to attitude toward treatment, compliance to treatment, and experience of stress and how they relate to either strengthening or weakening of therapeutic alliance.

\section{Supplementary Information}

The online version contains supplementary material available at https://doi.org/10.1186/s40723-021-00094-6.

Additional file 1.: Table S1. Mean scores, standard deviations, skewness, and kurtosis for scale variables $(n=124)$. Table S2. Hierarchical regression predicting parent-rated alliance with therapist with treatment attitude, treatment compliance, parental stress, and perceived ASD severity. Table S3. Hierarchical regression predicting caregiver-rated alliance with therapist with treatment attitude, treatment compliance, parental stress, and perceived ASD severity. Table S4. Hierarchical regression predicting parent-rated alliance with caregiver with parental stress and perceived ASD severity. Table S5. Hierarchical regression predicting caregiver-rated alliance with parent with caregiver stress and perceived ASD severity 


\section{Acknowledgments}

Not applicable.

\section{Author's contributions}

The author solely contributed to the a) conception and design of the work, b) acquisition, analysis, and interpretation of data, and c) drafting and revision of the final manuscript. The author has approved the submitted revision and has agreed to be personally accountable for his own contributions to the work. All authors read and approved the final manuscript.

\section{Funding}

This research received no specific grant from any funding agency in the public, commercial, or not-for-profit sectors.

\section{Data availability}

The data that support the findings of this study are openly available in figshare at https://doi.org/10.6084/m9.figshare. 8845625.v1

\section{Declarations}

\section{Competing interests}

The author declares that he has no competing interest

\section{Author details}

${ }^{1}$ Department of Psychology, University of the Philippines Diliman, National Capital Region, Philippines. ${ }^{2}$ Block 3 Lot 12 Kalikasan Hills Townhomes Barangay 171, 1421 Caloocan City, Philippines.

Received: 21 June 2020 Accepted: 13 December 2021

Published online: 10 January 2022

\section{References}

L Abbeduto MM Seltzer P Shattuck MW Krauss G Orsmond MM Murphy 2004 Psychological well-being and coping in mothers of youths with autism, down syndrome, or fragile X syndrome American Journal on Mental Retardation 1093237254 https://doi.org/10.1352/0895-8017(2004)109\%3C237:PWACIM\%3E2.0.CO;2.

Accurso, E. (2012). Therapeutic alliance and outcomes in usual care child psychotherapy [Doctoral dissertation, University of California]. ProQuest Dissertations and Theses Global.

E Accurso A Garland 2015 Child, caregiver, and therapist perspectives on therapeutic alliance in usual care child psychotherapy Psychological Assessment 271347352 https://doi.org/10.1037/pas0000031.

E Accurso K Hawley A Garland 2013 Psychometric Properties of the Therapeutic Alliance Scale for Caregivers and Parents Psychological Assessment 251244252 https://doi.org/10.1037/a0030551.

SJ Ackerman MJ Hilsenroth 2003 A review of therapist characteristics and techniques positively impacting the therapeutic alliance Clinical Psychology Review 23133 https://doi.org/10.1016/s0272-7358(02)00146-0.

Al-Dujaili, A., \& Al-Mossawy, D. (2017). Psychosocial burden among caregivers of children with autism spectrum disorder in Najaf province. Current Pediatrics Research, 21(2), 272-282. https://doi.org/10.20546/ijcrar.2017.504.018.

Alderson, J. (2009). Moving toward a multi-treatment approach to autism: The whole is greater than the sum of the parts. http://www.imti.ca/media/documents/AutismFileFinal_Jan09.pdf.

L Alexander M Dore 1999 Making the Parents as Partners principle a reality: The role of the alliance Journal of Child and Family Studies 83255270 https://doi.org/10.1023/A:1022059127934.

American Psychiatric Association. (2013). Diagnostic and statistical manual of mental disorders (5th ed.). https://doi.org/ 10.1176/appi.books.9780890425596.

Amtmann, D., Liljenquist, K. S., Bamer, A., Gammaitoni, A. R., Aron, C. R., Galer, B. S., Johnson, M. F., \& Jensen, M. P. (2017, November). Development of the Caregiver Stress Scale for Caregivers of Children with Epilepsy [Poster presentation] $71^{\text {st }}$ American Epilepsy Society Annual Meeting, Emeryville, CA. http://www.zogenix.com/wp-content/uploads/2018/ 11/AES_Poster_Caregiver-Stress-Scale_2017.pdf.

RB Ardito D Rabellino 2011 Therapeutic Alliance and Outcome of Psychotherapy: Historical Excursus, Measurements, and Prospects for Research Frontiers in Psychology 2270 https://doi.org/10.3389/fpsyg.2011.00270.

M Arnd-Caddigan 2012 The Therapeutic Alliance: Implications for Therapeutic Process and Therapeutic Goals Journal of Contemporary Psychotherapy 4227785 https://doi.org/10.1007/s10879-011-9183-3.

P Baillargeon WM Pinsof A Leduc 2005 Systemic model of therapeutic alliance Revue Europeenne De Psychologie Appliquee 553137143 https://doi.org/10.1016/j.erap.2004.09.001.

Bermudo, G. (2010, July 01). Yaya Inday, A Rare Gem. http://www.autismsocietyphilippines.org/2010/06/yaya-inday-raregem.html.

J Blacher LL McIntyre 2006 Syndrome specificity and behavioral disorders in young adults with intellectual disability: Cultural differences in family impact Journal of Intellectual Disability Research 50184198 https://doi.org/10.1111/j. 1365-2788.2005.00768.x.

E Bordin 1979 The generalizability of the psychoanalytic concept of the working alliance Psychotherapy: Theory Research and Practice 16252260 https://doi.org/10.1037/h0085885.

R Bouma R Schweitzer 1990 The impact of chronic childhood illness on family stress: A comparison between autism and cystic fibrosis Journal of Clinical Psychology 46722730 https://doi.org/10.1002/1097-4679(199011)46:6<722::AIDJCLP2270460605>3.0.CO;2-6. 
EV Brestan JR Jacobs AD Rayfield SM Eyberg 1999 A consumer satisfaction measure for parent-child treatments and its relation to measures of child behavior change Behavior Therapy 3011730 https://doi.org/10.1016/S0005-7894(99) 80043-4.

JB Brobst JR Clopton SS Hendrick 2009 Parenting children with autism spectrum disorders: The couple's relationship Focus on Autism and Other Developmental Disabilities 2413849 https://doi.org/10.1177/1088357608323699.

MB Broggi R Sabatelli 2010 Parental Perceptions of the Parent-Therapist Relationship: Effects on Outcomes of Early Intervention Physical and Occupational Therapy in Pediatrics 303234247 https://doi.org/10.3109/01942631003757602.

A Dabrowska E Pisula 2010 Parenting stress and coping styles in mothers and fathers of pre-school children with autism and Down syndrome Journal of Intellectual Disability Research 543266280 https://doi.org/10.1111/j.1365-2788. 2010.01258.x.

Davis, E. M. (2014). Perceived barriers and parental adherence to recommendations following child psychological assessment [Doctoral dissertation, University of Florida]. ProQuest Dissertations and Theses Global.

NO Davis AS Carter 2008 Parenting stress in mothers and fathers of toddlers with autism spectrum disorders: Associations with child characteristics Journal of Autism Developmental Disorders 38712781291 https://doi.org/10.1007/ s10803-007-0512-z.

M DeFilippis KD Wagner 2016 Treatment of autism spectrum disorder in children and adolescents Psychopharmacology Bulletin 4621841.

KA DeVet YJ Kim D Charlot-Swilley HT Ireys 2003 The therapeutic relationship in child therapy: Perspectives of children and mothers Journal of Clinical Child and Adolescent Psychology 322277283 https://doi.org/10.1207/S15374424J CCP3202 13.

R Diguiseppe J Linsicott R Jilton 1996 Developing the therapeutic alliance in child-adolescent psychotherapy Applied and Preventive Psychology 5285100 https://doi.org/10.1016/S0962-1849(96)80002-3.

AS Dreyer O Laughlin J Moore Z Milam 2010 Parental adherence to clinical recommendations in an ADHD evaluation clinic Journal of Clinical Psychology 661011011120 https://doi.org/10.1002/jclp.20718.

V Eapen R Črnčec A Walter KP Tay 2014 Conceptualization and development of a quality of life measure for parents of children with autism spectrum disorder Autism Research and Treatment 2014111 https://doi.org/10.1155/2014/ 160783.

J Elicker IC Noppe LD Noppe C Fortner-Wood 1997 The parent-caregiver relationship scale: Rounding out the relationship system in infant child care Early Education and Development 8183100 https://doi.org/10.1207/s15566935e ed0801_7.

S Eyberg 1993 Consumer satisfaction measures for assessing parent training programs L VandeCreek S Knapp TL Jackson Eds Innovations in clinical practice: A source book 12 Professional Resource Press/Professional Resource Exchange 377382.

SM Eyberg SM Johnson 1974 Multiple assessment of behavior modification with families: Effects of contingency contracting and order of treated problems Journal of Consulting and Clinical Psychology 424594606 https://doi.org/ 10.1037/h0036723.

NR Feinstein K Fielding A Udvari-Solner SV Joshi 2009 The supporting alliance in child and adolescent treatment: Enhancing collaboration among therapists, parents, and teachers American Journal of Psychotherapy $634319344 \mathrm{https}: / /$ doi.org/10.1176/appi.psychotherapy.2009.63.4.319.

Hawks, J. M. (2015). Exploring the Therapeutic Alliance with Adolescents and Their Caregivers: A Qualitative Approach [Doctoral dissertation, University of Kentucky]. Theses and Dissertations--Family Sciences. https://uknowledge.uky.edu/ hes etds/32.

S Helps 2016 Systemic psychotherapy with families where someone has an autism spectrum condition NeuroRehabilitation 383223230 https://doi.org/10.3233/NRE-161314.

KE Hoagwood 2005 Family-based services in children's mental health: A research review and synthesis Journal of Child Psychology and Psychiatry 467670713 https://doi.org/10.1111/j.1469-7610.2005.01451.x.

R Hock A Kinsman A Ortaglia 2015 Examining treatment adherence among parents of children with autism spectrum disorder Disability and Health Journal 83407413 https://doi.org/10.1016/..dhjo.2014.10.005.

Kalyva, E. (2013). Collaboration Between Parents of Children with Autism Spectrum Disorders and Mental Health Professionals. In M. Fitzgerald (Ed.), Recent Advances in Autism Spectrum Disordes - Volume I. InTech. https://doi.org/10.5772/ 53966.

EA Karam M Ko B Pinsof D Mroczek D Sprenkle 2015 The multisystemic and multilevel investigation of the expanded therapeutic alliance-psychological functioning relationship in individual therapy Journal of Marital and Family Therapy 414401414 https://doi.org/10.1111/jmft.12094.

AE Kazdin L Holland M Crowley 1997 Family experience of barriers to treatment and premature termination from child therapy Journal of Consulting and Clinical Psychology 65453463 https://doi.org/10.1037/0022-006X.65.3.453.

AE Kazdin M Whitley PL Marciano 2006 Child-therapist and parent-therapist alliance and therapeutic change in the treatment of children referred for oppositional, aggressive, and antisocial behavior Journal of Child Psychology and Psychiatry 47436445 https://doi.org/10.1111/j.1469-7610.2005.01475.x.

NM Kheir AL Sandridge SA Hayder MS Al-Ismail F Al-Rawi 2012 Concerns and considerations among caregivers of a child with autism in Qatar BMC Research Notes 5290 https://doi.org/10.1186/1756-0500-5-290.

T Krakovich J McGrew Y Yu L Ruble 2016 Stress in parents of children with autism spectrum disorder: An exploration of demands and resources Journal of Autism and Developmental Disorders 46620422053 https://doi.org/10.1007/ s10803-016-2728-2.

MJ Lambert BM Ogles 2004 The efficacy and effectiveness of psychotherapy M Lambert Eds Bergin and Garfield's Handbook of Psychotherapy and Behavior Change John Wiley and Sons Inc 139193.

AB Loper B Philipps EB Nichols DH Dallaire 2014 Characteristics and effects of the co-parenting alliance between incarcerated parents and child caregivers Journal of Child \& Family Studies 232225241 https://doi.org/10.1007/ s10826-012-9709-7.

L Luborsky 1994 Therapeutic alliances as predictors of psychotherapy outcomes: Factors explaining the predictive process AO Horvath LS Greenberg Eds The working alliance: Theory, research and practice John Wiley \& Sons 5184. 
S Menahem G Halasz 2000 Parental non-compliance: a paediatric dilemma. A medical and psychodynamic perspective Child Care Health and Development 2616172 https://doi.org/10.1046/j.1365-2214.2000.00115.x.

M Mulsow YM Caldera M Pursley A Reifman AC Huston 2002 Multilevel factors influencing maternal stress during the first three years Journal of Marriage and Family 644944956 https://doi.org/10.1111/j.1741-3737.2002.00944.x.

Myers, S. J. (2008). Relationship between the consultant-parent working alliance and ratings of the consultation process with parents of children having autism spectrum disorder [Doctoral dissertation, University of Arizona]. Proquest Dissertations and Theses Global.

C Panter-Brick A Burgess M Eggerman F McAllister K Pruett JF Leckman 2014 Practitioner Review: Engaging fathers - recommendations for a game change in parenting interventions based on a systematic review of the global evidence Journal of Child Psychology and Psychiatry 551111871212 https://doi.org/10.1111/jcpp.12280.

WM Pinsof 1994 An integrative systems perspective on the therapeutic alliance: Theoretical, clinical and research implications A Horvath L Greenberg Eds The working alliance: Theory, research and practice John Wiley \& Sons 173195.

Rabideau, A. (2017). Caregiver descriptions of services received for children with autism and the impact on family life: A case study [Doctoral dissertation, Capella University]. ProQuest Dissertations and Theses Global.

C Raffin 2001 A multidisciplinary approach to working with autistic children Educational and Child Psychology 18215 27.

Rodriguez, N. (2011). The Parent-Therapist Alliance in the Psychological Treatment of Children [Doctoral thesis, University College London]. UCL Discovery. https://discovery.ucl.ac.uk/id/eprint/1324496.

SA Rone-Adams DF Stern V Walker 2004 Stress and compliance with a home exercise program among caregivers of children with disabilities Pediatric Physical Therapy 163140148 https://doi.org/10.1097/01.PEP.0000136006.13449.DC.

SR Shirk M Karver 2003 Prediction of treatment outcome from relationship variables in child and adolescent therapy: A meta-analytic review Journal of Consulting and Clinical Psychology 71452464 https://doi.org/10.1037/0022-006X. 71.3.452.

Smithson, S. (2009). Attitudes toward Treatment: The Effects of Viewing Sequential TV Portrayals of Psychotherapy [Undergraduate Research, University of British Columbia]. UBC Library. https://open.library.ubc.ca/clRcle/collections/under graduateresearch/52966/items/1.0086042.

Sullivan, J. M. (2011). Parents of children with high-functioning autism: Experiences in child-parent relationship therapy (CPRT) [Doctoral dissertation, University of North Texas]. Proquest Dissertations and Theses Global.

LE Taylor KM Antshel 2019 Factors associated with parental treatment attitudes and information-seeking behaviors for childhood ADHD Journal of Attention Disorders 91087054718821734 https://doi.org/10.1177/1087054718821734.

SJ Thompson K Bender J Lantry PM Flynn 2007 Treatment engagement: building therapeutic alliance in home-based treatment with adolescents and their families Contemporary Family Therapy 29 1-2 3955 https://doi.org/10.1007/ s10591-007-9030-6.

Walter, U., \& Petr, C. (2006, March). Therapeutic Alliance with Children and Families: A Review of the National Literature. State of Kansas, Department of Social and Rehabilitation Services. https://kuscholarworks.ku.edu/bitstream/handle/1808/ 3884/bestpracticesreport16.pdf;jsessionid=203B706COABCB73D7BFFACA0ED52ECF6? sequence $=1$.

Wampold, B. E. (2001). The great psychotherapy debate: Models, methods and findings. Lawrence Erlbaum Publishers.

SL Watson SA Hayes E Radford-Paz 2011 'Diagnose me please!': A review of research about the journey and initial impact of parents seeking a diagnosis of developmental disability for their child International Review of Research in Developmental Disabilities 413172 https://doi.org/10.1016/B978-0-12-386495-6.00002-3.

RV Weersing JR Weisz 2002 Mechanisms of action in youth psychotherapy Journal of Child Psychology and Psychiatry 43 1329 https://doi.org/10.1111/1469-7610.00002.

SWeissman RS Cohen 1985 The parenting alliance and adolescence Adolescent Psychiatry 122445.

LC Wolf S Noh SN Fisman M Speechley 1989 Psychological effects of parenting stress on parents of autistic children Journal of Autism and Developmental Disorders 191157166 https://doi.org/10.1007/BF02212727.

\section{Publisher's Note}

Springer Nature remains neutral with regard to jurisdictional claims in published maps and institutional affiliations.

\section{Submit your manuscript to a SpringerOpen ${ }^{\circ}$ journal and benefit from:}

- Convenient online submission

- Rigorous peer review

- Open access: articles freely available online

- High visibility within the field

Retaining the copyright to your article

Submit your next manuscript at $\boldsymbol{s p r i n g e r o p e n . c o m ~}$ 